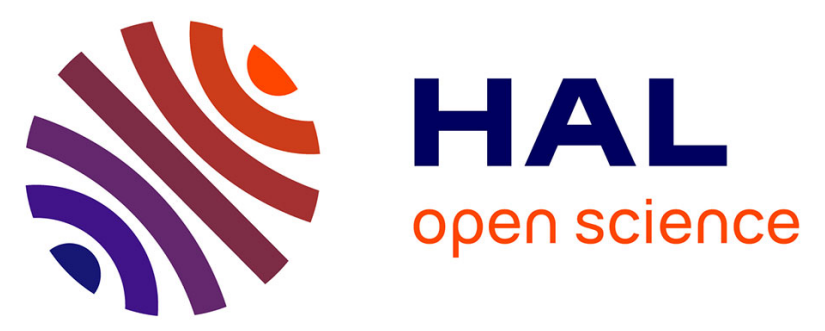

\title{
Prediction of cyclohexane-water distribution coefficients for the SAMPL5 data set using molecular dynamics simulations with the OPLS-AA force field
}

Ian M Kenney, Oliver Beckstein, Bogdan Iorga

\section{- To cite this version:}

Ian M Kenney, Oliver Beckstein, Bogdan Iorga. Prediction of cyclohexane-water distribution coefficients for the SAMPL5 data set using molecular dynamics simulations with the OPLS-AA force field. Journal of Computer-Aided Molecular Design, 2016, 30 (11), pp.1045-1058. 10.1007/s10822016-9949-5 . hal-02377129

\section{HAL Id: hal-02377129 \\ https://hal.science/hal-02377129}

Submitted on 23 Nov 2019

HAL is a multi-disciplinary open access archive for the deposit and dissemination of scientific research documents, whether they are published or not. The documents may come from teaching and research institutions in France or abroad, or from public or private research centers.
L'archive ouverte pluridisciplinaire HAL, est destinée au dépôt et à la diffusion de documents scientifiques de niveau recherche, publiés ou non, émanant des établissements d'enseignement et de recherche français ou étrangers, des laboratoires publics ou privés. 


\title{
Prediction of cyclohexane-water distribution coefficients for the SAMPL5 data set using molecular dynamics simulations with the OPLS-AA force field
}

\author{
Ian M. Kenney · Oliver Beckstein · Bogdan I. \\ Iorga
}

Received: date / Accepted: date

\begin{abstract}
All-atom molecular dynamics (MD) simulations were used to predict watercyclohexane distribution coefficients $D_{c w}$ of a range of small molecules as part of the SAMPL5 blind prediction challenge. Molecules were parameterized with the transferable all-atom OPLS-AA force field, which required the derivation of new parameters for sulfamides and heterocycles and validation of cyclohexane parameters as a solvent. The distribution coefficient was calculated from the solvation free energies of the compound in water and cyclohexane. Absolute solvation free energies were computed by an established protocol using windowed alchemical free energy perturbation with thermodynamic integration. This protocol resulted in an overall root mean square error (RMSE) in $\log D_{c w}$ of almost $4 \log$ units and an overall signed error of -3 compared to experimental data. There was no substantial overall difference in accuracy between simulating in $N V T$ and $N P T$ ensembles. The signed error suggests a systematic error but the experimental $D_{c w}$ data on their own are insufficient to
\end{abstract}

OB was supported in part by grant ACI-1443054 from the National Science Foundation. BII was supported in part by grants ANR-10-LABX-33 (LabEx LERMIT) and ANR-14-JAMR-0002-03 (JPIAMR) from the French National Research Agency (ANR).

I. M. Kenney

Department of Physics, Arizona State University, P.O. Box 871504, Tempe, AZ 85287-1504, USA

O. Beckstein

Department of Physics and Center for Biological Physics, Arizona State University, P.O. Box 871504, Tempe, AZ 85287-1504, USA

Tel.: +1 4807279765

Fax: $+1480965-4669$

E-mail: oliver.beckstein@asu.edu

B. I. Iorga

Institut de Chimie des Substances Naturelles, CNRS UPR 2301, Université Paris-Saclay, Labex LERMIT, 1 Avenue de la Terrasse, 91198 Gif-sur-Yvette, France

Tel.: +33169823094

Fax: +3316907 7247

E-mail: bogdan.iorga@cnrs.fr 
uncover the source of this error. Preliminary work suggests that the major source of error lies in the hydration free energy calculations.

Keywords molecular dynamics - solvation free energy - OPLS-AA force field . ligand parameterization · free energy perturbation - thermodynamic integration . cyclohexane-water distribution coefficients

\section{Introduction}

The distribution coefficient $D_{A B}$ of a small molecule quantifies the partitioning of a molecule between two immiscible phases $A$ and $B$. Of particular importance in drug discovery are distribution coefficients between the aqueous phase and hydrophobic solvents, which mimic to some degree biological hydrophobic environments such as the lipid bilayer of the cell membrane. Distribution coefficients can be used to describe and model the distribution of molecules in chemical and biological systems. In the drug discovery process, they are key quantities for the design of drugs that can diffuse across cell membranes (blood brain barrier, epithelial lining of the gut) and thus reach their site of action inside the body or a cell itself [1].

In principle, distribution coefficients should also be good benchmark systems for the evaluation of the predictive power of quantitative computational methods [2], similar to the hydration free energy calculations of previous SAMPL challenges [371.

For the SAMPL5 challenge we employed classical all-atom molecular dynamics (MD) simulations in explicit solvent with additive and transferable force fields to predict distribution coefficients. We are also interested in the question if distribution coefficients might be useful target observables in the process of parameterizing small molecules and drug-like compounds.

The data set provided for the SAMPL5 challenge consisted of 53 small, drug-like molecules (Figures $1 \mathrm{a}$ and $1 \mathrm{~b}$ ) for which water-cyclohexane distribution coefficients [8] were measured at Genentech using a mass spectrometry-based assay [9]. Their distribution coefficients had not been published but were known to the SAMPL5 organizers.

Here we employed explicit solvent MD simulations in conjunction with a windowed alchemical free energy perturbation approach to compute absolute solvation free energies of the compounds in water $\left(\Delta G_{w}\right)$ and cyclohexane $\left(\Delta G_{c}\right)$. The cyclohexanewater partition coefficient $D_{c w}$ (or rather, its base-10 logarithm, indicated by log) is then

$$
\log D_{c w}=\left(\Delta G_{w}-\Delta G_{c}\right)(k T)^{-1} \log e,
$$

where $k=1.987207 \times 10^{-3} \mathrm{kcal} \cdot \mathrm{mol}^{-1} \cdot \mathrm{K}^{-1}$ is Boltzmann's constant, $T$ is the temperature, and $e$ Euler's number. If $\log D_{c w}$ is zero then the solute is equally likely to be found in the water and the cyclohexane phase. $\mathrm{A} \log D_{c w}<0$ indicates that the polar water phase is favored whereas for $\log D_{c w}>0$ the hydrophobic cyclohexane is preferred.

The interactions between all atoms in the system were parameterized on the basis of the classical OPLS-AA force field [10]. OPLS-AA is a transferable force field 
<smiles>CCOC(=O)c1sc2nc(C)c(C)c(C)c2c1C</smiles><smiles>O=c1oc(-c2ccccc2I)nc2ccccc12</smiles><smiles>CCOc1ccc(Nc2cc(C)c3ccccc3n2)cc1</smiles><smiles>Cn1ccnc1SCC(=O)Nc1ccc2c(c1)OCO2</smiles><smiles>C=C(F)Cn1c(CBr)nc2ccccc21</smiles><smiles>Cc1ccc2ncnc(NCCc3ccccc3)c2c1</smiles><smiles>O=C(O)c1cccc(NCc2ccncc2)c1</smiles><smiles>Cc1cc(C)nc(Nc2ccccc2C(=O)O)n1</smiles><smiles>Cc1ccc(-c2nc(C(N)=O)c3nc(C)n(-c4ccccc4)c3n2)cc1</smiles><smiles>Cc1ccc2ncnc(NCC(N)=O)c2c1</smiles><smiles>Oc1ccccc1-c1nc(NC2CCCC2)c2ccccc2n1</smiles><smiles>Cc1ccc(Nc2cccc(Nc3ccc(C)cc3)n2)cc1</smiles><smiles>CCCC(=O)Nc1nc2ccc(C(C)C)cc2s1</smiles><smiles>COc1cccc(-c2cn3[nH]c(C)cc3n2)c1</smiles><smiles>Cc1ccc2nc3sc(C(=O)Nc4ccc(C)c(C)c4)cc3cc2c1</smiles><smiles>Cc1cc(C)c2[nH]c(C)c(CC(=O)O)c2c1</smiles><smiles>Cc1ncnc(NCc2ccccc2)n1</smiles><smiles>Cc1ccc(Cl)cc1NC(=O)N1CCCCCC1c1ccccc1</smiles><smiles>CC1CCN(C(=O)C2CCNCC2)C1</smiles><smiles>O=C(Nc1ccccn1)c1ccccc1-c1ccccc1</smiles><smiles>O=C(Nc1ccc2ncsc2c1)c1cc2ccccc2oc1=O</smiles>

${ }^{033}$<smiles>CCC(=O)Nc1ccc2scnc2c1</smiles>

045<smiles>CCc1ccc(CC(=O)Nc2ccnc3sccc23)cc1</smiles><smiles>N#Cc1c(NC(=O)c2ccno2)sc2c1CCCC2</smiles><smiles>O=C(Nc1cccc(-c2nc3ccccc3s2)c1)c1ccccc1</smiles>

1a Chemical structures of the 53 compounds included in the SAMPL5 data set.

with partial atomic charges determined from calculations on small model compounds; unlike other classical force fields, these partial charges are considered fixed and part of the atom type in the same way as the Lennard-Jones potential parameters. This leads to a rich set of atom types that can be directly applied to an atom in another molecule that experiences the same chemical environment as the atom in the model compound. Thus, in principle OPLS-AA is a good force field for the parameterization of small molecules based on chemical rules without the requirement of moleculespecific adaptations such as additional partial charge calculations. 
<smiles>CC(Nc1ccccc1O)c1ccccc1</smiles>

049<smiles></smiles><smiles>Cc1cccc(-c2ccccc2)c1</smiles><smiles>Cc1cc2c(cc1C)CC(C(C)C)CC2</smiles><smiles></smiles>

058<smiles>Cc1cccc(C2(C)CCCCC2)c1</smiles><smiles>CC(=O)C1CCC(C2CCCCC2)CC1</smiles>

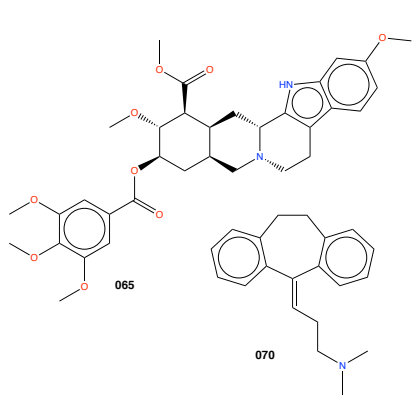<smiles>CC(C)CCC(C)CCc1cccc2ccccc12</smiles><smiles>c1ccc(-c2cnc(-c3ccccc3)c(-c3ccccc3)c2)cc1</smiles>

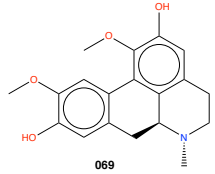<smiles>CCCc1cc(C2CCCCC2)c(CCC)cc1C</smiles><smiles>CC(C)CCCC(c1ccccc1)c1ccccc1</smiles><smiles>CCC1CC(c2ccc3c(C)cccc3c2)C(C)C1C</smiles><smiles>COCCc1ccc(CCC(C)CCC(C)C)cc1</smiles><smiles></smiles>

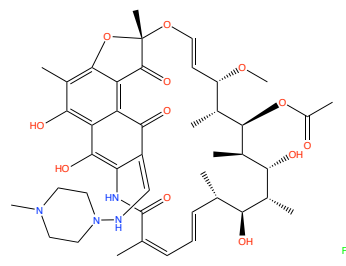<smiles>Cc1ccc(C2(S)CCC(CCCC(=O)c3ccccc3)CC2)cc1</smiles><smiles>CCCCCOc1cc(C(C)C(C)CCCC(CC)CC)c2ccccc2c1</smiles><smiles>C=C(C(CC)Cc1ccccc1)C(CC)c1ccccc1</smiles><smiles>Cc1cc2cc(-c3ccccc3)c(-c3ccccc3)cc2cc1C</smiles>

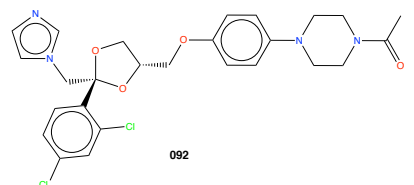

$1 \mathrm{~b}$ Chemical structures of the 53 compounds included in the SAMPL5 data set (continued).

\section{Methods}

Calculations were performed with protocols similar to our previous work in the SAMPL3 [11] and SAMPL4 [12] challenges but for completeness we describe the essential details below. 
<smiles>CN(C)S(=O)(=O)N(C)C</smiles>

A<smiles>O=c1cccn[nH]1</smiles><smiles>C1=CCC=C1</smiles><smiles>c1cnncn1</smiles><smiles></smiles><smiles>c1nncs1</smiles>

$\mathrm{E}$

Fig. 2: Chemical structures of the motifs for which new OPLS-AA parameters had to be generated; see Table 1 for the parameters.

\subsection{Force field parameters}

The SAMPL5 data set contained 53 compounds (see Figures $1 \mathrm{a}$ and $1 \mathrm{~b}$ together with their SAMPL5 ID numbers), which were parameterized in the protonation and tautomeric forms as provided by the organizers, with the exception of compound 042 for which tautomeric forms were considered (see below). The SMILES string of each compound was converted to PDB format with CORINA version 3.60 (http:// www.molecular-networks.com). Molecules were parameterized with the OPLSAA all-atom force field [13-19]. The OPLS-AA force field files that were bundled with Gromacs 4.6.5 [20, 21] were used as a starting point and extended with parameters found in the literature [11, 12, 22,-28]. Topologies were generated using the MOL2FF algorithm (O. Beckstein and B. I. Iorga, unpublished), which automatically assigns OPLS-AA atom types based on the chemical function as determined by the CACTVS Chemoinformatics Toolkit (http://www . xemistry.com/). All force field parameters for the SAMPL5 compounds were deposited in the Ligandbook repository https://ligandbook .org [29] (see Table 3 for the individual LigandbookIDs).

The OPLS-AA force field has been parameterized together with the TIP4P water model [13,19] and in order to remain consistent with this standard choice, we also employed the standard TIP4P parameters [30]. For simulations with cyclohexane we generated parameters with MOL2FF and tested them with simulations of bulk cyclohexane (see Results).

\subsection{Parameterization of missing OPLS-AA parameters}

Force field parameters were not available in the published OPLS-AA force field for a number of chemical groups ( $\mathrm{N}$-substituted sulfamide, $2 \mathrm{H}$-pyridazin-3-one, thiophene, 1,2,4-triazine, 1,2,4-thiadiazole and 1,3,4-thiadiazole, see Figure 2p that were present in the SAMPL5 data set. CM5-derived charges were calculated for these chemical groups using Gaussian09 (revision D.01) [31] and following the protocol recently described by Jorgensen and colleagues [32, 33], with a scaling factor of 1.20. These newly generated parameters are presented in Table 1 . When necessary, other missing atom types, bond, angle and dihedral bonding parameters were adapted from the existing ones using the original OPLS-AA philosophy or obtained in a manner similar to the published OPLS-AA protocol [14]. 
Table 1: New OPLS-AA parameters for $\mathrm{N}$-substituted sulfamide, $2 \mathrm{H}$-pyridazin-3-one, thiophene, 1,2,4-triazine, 1,2,4-thiadiazole and 1,3,4-thiadiazole chemical groups (CM5 charges).

\begin{tabular}{|c|c|c|c|c|c|c|c|}
\hline name $^{\mathrm{a}}$ & type $^{b}$ & $Z^{\mathrm{c}}$ & $m(\mathrm{u})^{\mathrm{d}}$ & $q(e)^{\mathrm{e}}$ & $\sigma(\mathrm{nm})^{\mathrm{f}}$ & $\varepsilon\left(\mathrm{kJ} \cdot \mathrm{mol}^{-1}\right)^{\mathrm{g}}$ & \\
\hline opls_474A & SY & 16 & 32.0600 & 0.852 & 0.355 & 1.046000 & ; $\mathbf{S}$ in sulfamide \\
\hline opls_475A & OY & 8 & 15.9994 & -0.444 & 0.296 & 0.711280 & ; $\mathbf{O}$ in sulfamide \\
\hline opls_480A & $\mathrm{N}$ & 7 & 14.0067 & -0.464 & 0.325 & 0.711280 & $; \mathbf{N}$ in sulfamide \\
\hline opls_483A & $\mathrm{HC}$ & 1 & 1.0080 & 0.132 & 0.250 & 0.125520 & ; $\mathrm{CH}_{x}-\mathrm{N}$ in sulfamide \\
\hline opls_482A & $\mathrm{CT}$ & 6 & 12.0110 & -0.155 & 0.350 & 0.276144 & $; \mathbf{C H}_{3}-\mathrm{N}$ in sulfamide \\
\hline opls_484A & $\mathrm{CT}$ & 6 & 12.0110 & -0.023 & 0.350 & 0.276144 & ; $\mathrm{RCH}_{2}-\mathrm{N}$ in sulfamide \\
\hline opls_484B & $\mathrm{CT}$ & 6 & 12.0110 & 0.109 & 0.350 & 0.276144 & $; \mathrm{R}_{2} \mathrm{CH}-\mathrm{N}$ in sulfamide \\
\hline opls_484C & $\mathrm{CT}$ & 6 & 12.0110 & 0.241 & 0.350 & 0.276144 & $; \mathrm{R}_{3} \mathrm{C}-\mathrm{N}$ in sulfamide \\
\hline opls_750A & $\mathrm{NZ}$ & 7 & 14.0067 & -0.282 & 0.325 & 0.711280 & ; $\mathrm{N} 1$ in $2 H$-pyridazin-3-one \\
\hline opls_238A & $\mathrm{N}$ & 7 & 14.0067 & -0.352 & 0.325 & 0.711280 & ; N2 in $2 H$-pyridazin-3-one \\
\hline opls_235A & $\mathrm{C}$ & 6 & 12.0110 & -0.312 & 0.375 & 0.439320 & ; $\mathrm{C} 3$ in $2 \mathrm{H}$-pyridazin-3-one \\
\hline opls_142A & $\mathrm{CM}$ & 6 & 12.0110 & -0.088 & 0.355 & 0.317984 & ; $\mathrm{C} 4$ in $2 \mathrm{H}$-pyridazin-3-one \\
\hline opls_142B & $\mathrm{CM}$ & 6 & 12.0110 & -0.084 & 0.355 & 0.317984 & ; $\mathrm{C} 5$ in $2 \mathrm{H}$-pyridazin-3-one \\
\hline opls_277A & C_2 & 6 & 12.0110 & 0.060 & 0.375 & 0.439320 & ; C6 in $2 \mathrm{H}$-pyridazin-3-one \\
\hline opls_236A & $\mathrm{O}$ & 8 & 15.9994 & -0.456 & 0.296 & 0.878640 & ; $\mathrm{O} 3$ in $2 \mathrm{H}$-pyridazin-3-one \\
\hline opls_241A & $\mathrm{H}$ & 1 & 1.0080 & 0.434 & 0.000 & 0.000000 & ; $\mathrm{H} 2$ in $2 \mathrm{H}$-pyridazin-3-one \\
\hline opls_144A & $\mathrm{HC}$ & 1 & 1.0080 & 0.154 & 0.242 & 0.125520 & ; $\mathrm{H} 4$ in $2 \mathrm{H}$-pyridazin-3-one \\
\hline opls_144B & $\mathrm{HC}$ & 1 & 1.0080 & 0.146 & 0.242 & 0.125520 & ; $\mathrm{H} 5$ in $2 \mathrm{H}$-pyridazin-3-one \\
\hline opls_279A & $\mathrm{HC}$ & 1 & 1.0080 & 0.156 & 0.242 & 0.062760 & ; H6 in $2 \mathrm{H}$-pyridazin-3-one \\
\hline opls_633A & $\mathrm{S}$ & 16 & 32.0600 & 0.104 & 0.355 & 1.046000 & ; $\mathrm{S}$ in thiophene \\
\hline opls_567A & $\mathrm{CW}$ & 6 & 12.0110 & -0.172 & 0.355 & 0.292880 & ; 2 in thiophene \\
\hline opls_568A & $\mathrm{CS}$ & 6 & 12.0110 & -0.152 & 0.355 & 0.317984 & ; C3 in thiophene \\
\hline opls_569A & HA & 1 & 1.0080 & 0.140 & 0.242 & 0.125520 & ; H2 in thiophene \\
\hline opls_570A & HA & 1 & 1.0080 & 0.132 & 0.242 & 0.125520 & ; H3 in thiophene \\
\hline opls_641A & $\mathrm{N}$ & 7 & 14.0067 & -0.244 & 0.325 & 0.711280 & ; N1 in 1,2,4-triazine \\
\hline opls_641B & $\mathrm{N}$ & 7 & 14.0067 & -0.264 & 0.325 & 0.711280 & ; N2 in 1,2,4-triazine \\
\hline opls_642A & CQ & 6 & 12.0110 & -0.248 & 0.355 & 0.292880 & ; C3 in 1,2,4-triazine \\
\hline opls_641C & $\mathrm{N}$ & 7 & 14.0067 & -0.422 & 0.325 & 0.711280 & ; N4 in 1,2,4-triazine \\
\hline opls_145A & $\mathrm{CA}$ & 6 & 12.0110 & 0.106 & 0.355 & 0.292880 & ; C5 in 1,2,4-triazine \\
\hline opls_145B & $\mathrm{CA}$ & 6 & 12.0110 & 0.077 & 0.355 & 0.292880 & ; C6 in 1,2,4-triazine \\
\hline opls_643A & HA & 1 & 1.0080 & 0.174 & 0.242 & 0.125520 & ; H3 in 1,2,4-triazine \\
\hline opls_643B & HA & 1 & 1.0080 & 0.163 & 0.242 & 0.125520 & ; H5 in 1,2,4-triazine \\
\hline opls_643C & HA & 1 & 1.0080 & 0.162 & 0.242 & 0.125520 & ; H6 in 1,2,4-triazine \\
\hline opls_633B & $\mathrm{S}$ & 16 & 32.0600 & 0.284 & 0.355 & 1.046000 & ; $\mathrm{S}$ in 1,2,4-thiadiazole \\
\hline opls_635A & NB & 7 & 14.0067 & -0.443 & 0.325 & 0.711280 & ; N2 in 1,2,4-thiadiazole \\
\hline opls_634A & $\mathrm{CR}$ & 6 & 12.0110 & 0.211 & 0.355 & 0.292880 & ; C3 in 1,2,4-thiadiazole \\
\hline opls_635B & NB & 7 & 14.0067 & -0.461 & 0.325 & 0.711280 & ; N4 in $1,2,4$-thiadiazole \\
\hline opls_634B & $\mathrm{CR}$ & 6 & 12.0110 & 0.058 & 0.355 & 0.292880 & ; C5 in 1,2,4-thiadiazole \\
\hline opls_638A & HA & 1 & 1.0080 & 0.178 & 0.242 & 0.125520 & ; H3 in 1,2,4-thiadiazole \\
\hline opls_638B & HA & 1 & 1.0080 & 0.173 & 0.242 & 0.125520 & ; H5 in 1,2,4-thiadiazole \\
\hline opls_633C & $\mathrm{S}$ & 16 & 32.0600 & 0.118 & 0.355 & 1.046000 & ; $\mathrm{S}$ in 1,3,4-thiadiazole \\
\hline opls_634C & $\mathrm{CR}$ & 6 & 12.0110 & 0.067 & 0.355 & 0.292880 & ; C2 in 1,3,4-thiadiazole \\
\hline opls_635C & NB & 7 & 14.0067 & -0.301 & 0.325 & 0.711280 & ; N3 in $1,3,4$-thiadiazole \\
\hline opls_638C & $\mathrm{HA}$ & 1 & 1.0080 & 0.175 & 0.242 & 0.125520 & ; $\mathrm{H} 2$ in $1,3,4$-thiadiazole \\
\hline
\end{tabular}

${ }^{\mathrm{a}}$ proposed OPLS-AA atom type name $\quad{ }^{\mathrm{b}}$ bonded type $\quad{ }^{\mathrm{c}}$ atomic number

${ }^{\mathrm{d}}$ atomic mass in atomic mass units $m_{\mathrm{u}}=1.660538921 \times 10^{-27} \mathrm{~kg} \quad{ }^{\mathrm{e}}$ partial charge in elementary charges $e=1.602176565 \times 10^{-19} \mathrm{C}$

${ }^{\mathrm{f}}$ length parameter of the OPLS-AA Lennard-Jones potential $\left.V_{\mathrm{LJ}}(r)=4 \varepsilon\left[(\sigma / r)^{12}-(\sigma / r)^{6}\right)\right][10]$

g energy well depth of the OPLS-AA Lennard-Jones potential $V_{\mathrm{LJ}}(r)$ 
In this SAMPL5 challenge we tentatively evaluated the parameterization of fused rings (for which no parameters are available in the OPLS-AA force field) using the parameters of the individual rings. This approach is not fully validated yet, but if it proves to be useful it will greatly facilitate the parameterization of new heterocyclic systems and-following the OPLS-AA philosophy-extend the modularity and the transferability of the parameters.

Compound 042 also provided a good opportunity to test the parameterization of two alternative tautomeric forms of a heterocycle, i.e., aromatic (3-hydroxy-pyridazine) and non-aromatic (2H-pyridazin-3-one, which represents the structure provided in the SAMPL5 data set).

From the parameterization point of view, the compounds from the SAMPL5 data set can be classified in four groups: group 1, with compounds containing chemical moieties available in the OPLS-AA force field: 004, 010, 011, 019, 026, 027 , 049, 056, 061, 063, 065, 067, 069, 070, 071, 072, 074, 075, 081, 082, 084, 086, 088; group 2, with compounds containing chemical moieties absent from the OPLS-AA force field, that were parameterized during this work: 005, 033, 042, 047 , 059, 068, 092; group 3, with compounds containing fused rings for which parameterization used the parameters of individual rings: 007, 015, 017, 020, 044, 045, 048, 050, 055, 060, 090; group 4, with compounds presenting a combination of the issues mentioned above, chemical moieties difficult to parameterize, and high conformational complexity: 002, 003, 006, 013, 021, 024, 037, 046, 058, 080, 083, 085.

During the SAMPL5 challenge preliminary calculations of $\log D_{c w}$ for a few simple compounds with known solvation free energies in water and cyclohexane $\left(\Delta G_{w}\right.$ and $\Delta G_{c}$ ) showed that the distribution coefficient could be predicted with an error of about $0.9 \log \mathrm{D}$ units (data not shown). In our submission of the SAMPL5 predictions, this value was used as estimated uncertainty of the method for groups 1 and 2, and was increased arbitrarily to 1.1 and 1.3 for groups 3 and 4 to account for the more difficult parameterization.

\subsection{Conformational flexibility}

Considering the size and the macrocyclic structure of compound 083, two different conformations (the one provided in the SAMPL5 data set and a second one, generated using CORINA) were considered as input structures for our protocol. By using different starting structures for the simulations we wanted to evaluate the sensitivity of the results to the initial conditions.

\subsection{Hydration free energy and distribution coefficient calculation}

Solvation free energies were calculated via alchemical free energy perturbation (FEP) MD simulations of each molecule in a water box. All simulations were performed with the MDPOW Python package (https://github.com/Becksteinlab/MDPOW) with Gromacs 4.6.5 [21, 34] as its MD engine. A periodic rhombic dodecahedral simulation cell was employed. In simulations with water, the minimum distance between 
a solute and a box face was $1 \mathrm{~nm}$ whereas this distance was increased to $1.5 \mathrm{~nm}$ for cyclohexane as solvent.

The simulations were run as Langevin dynamics (integration time step $2 \mathrm{fs}$ ) for temperature control, with the friction coefficient for each particle computed as mass $/ 0.1 \mathrm{ps}$ [35]. For simulations in the $N P T$ ensemble, the average pressure was maintained near the target value 1 bar with an isotropic Parrinello-Rahman barostat [36] with relaxation time constant $\tau_{p}=1 \mathrm{ps}$ and compressibility $\kappa_{T}=4.6 \times 10^{-5} \mathrm{bar}^{-1}$. The gridbased neighbor list was updated every five time steps. Lennard-Jones interactions were calculated up to a cutoff of $1 \mathrm{~nm}$ and a dispersion correction was applied to energy and pressure to account for van der Waals interactions beyond the cutoff in a mean field manner [37]. Coulomb interactions were evaluated with the SPME method [38] with a short range cutoff of $1 \mathrm{~nm}, 0.12 \mathrm{~nm}$ Fourier grid spacing, sixth order spline interpolation, and a relative tolerance of $10^{-6}$. All bonds containing hydrogen atoms were constrained with the P-LINCS algorithm [39] using a twelfth order expansion with a single iteration.

Solvated systems were energy minimized and carefully relaxed with an MD simulation with a time step of $0.1 \mathrm{fs}$ and duration of $5 \mathrm{ps}$. An initial equilibrium simulation at constant temperature and pressure $(T=300 \mathrm{~K}, P=1 \mathrm{bar})$ was carried out for $15 \mathrm{~ns}$. The last frame of the equilibrium simulation served as the starting configuration for the windowed FEP calculations. The FEP calculations were carried out (1) in the $N V T$ ensemble and (2) in the NPT ensemble; in previous work we had exclusively used the $N V T$ ensemble for the FEP calculations [11, 12] so we wanted to evaluate if there was a measurable difference between results from the two ensembles. Coulomb interactions (partial charges) were linearly switched off over five windows (coupling parameter $\lambda_{\text {Coul }} \in\{0,0.25,0.5,0.75,1\}$ ) while the van der Waals (Lennard-Jones) interactions were maintained (i.e. $\lambda_{\mathrm{vdW}}=0$ ); sixteen windows were used to switch off the Lennard-Jones term for the uncharged solute $\left(\lambda_{\text {Coul }}=1\right.$ and $\lambda_{\mathrm{vdW}} \in\{0,0.05$, $0.1,0.2,0.3,0.4,0.5,0.6,0.65,0.7,0.75,0.8,0.85,0.9,0.95,1\})$. Each window was simulated for $5 \mathrm{~ns}$. The van der Waals calculations used soft core potentials with the values suggested by Mobley and colleagues [35] $(\alpha=0.5$, power 1 , and $\sigma=0.3 \mathrm{~nm})$. The calculations made use of the "couple-intramol = no" feature in Gromacs [20, 21, 34], which maintains intramolecular interactions while decoupling all intermolecular ones. Solvation free energies and statistical errors for the discharging and decoupling process were calculated with thermodynamic integration

$$
\Delta G=\int_{0}^{1}\left\langle\frac{\partial \mathscr{H}}{\partial \lambda}\right\rangle d \lambda
$$

where the derivative of the Hamiltonian $\mathscr{H}$ with respect to the coupling parameter $\lambda$, $\partial \mathscr{H} / \partial \lambda$, was saved for every time step. Eq. 2 was integrated numerically with the composite Simpson's rule [40] as implemented in SciPy (http://www.scipy.org) [41]. The error on $\Delta G$ was calculated by propagating the errors of the individual $\langle\partial \mathscr{H} / \partial \lambda\rangle$ FEP windows through Simpson's rule as described previously [11].

The total solvation free energy (transfer from gas phase to aqueous phase at the $1 \mathrm{M} / 1 \mathrm{M}$ Ben-Naim standard state)

$$
\Delta G_{\mathrm{solv}}=-\left(\Delta G_{\mathrm{Coul}}+\Delta G_{\mathrm{vdW}}\right)
$$


is the sum of the Coulomb and van der Waals contributions, with the minus sign originating from the convention in Gromacs that $\lambda=0$ corresponds to the fully coupled (solvated) state while $\lambda=1$ describes a fully decoupled (gas-phase) solute.

In principle the distribution coefficient contains an average over all protonation and tautomeric states of the compound, which we do not take into account in our calculations. Instead we are calculating solvation free energies (Eq. 3 for one fixed state of the compound. The corresponding partition coefficient

$$
\log P_{c w}=\left(\Delta G_{w}-\Delta G_{c}\right)(k T)^{-1} \log e
$$

is only valid for the specific state of the molecule but we nevertheless make the approximation

$$
\log D_{c w} \approx \log P_{c w}
$$

\subsection{Error analysis}

The error $\varepsilon$ on $\log D_{c w}$ was calculated by error propagation from the errors of the individual free energies as

$$
\varepsilon=\sqrt{\varepsilon_{\Delta G_{c}}^{2}+\varepsilon_{\Delta G_{w}}^{2}}(k T)^{-1} \log _{10} e .
$$

The difference between experimental and computed water-cyclohexane distribution coefficients ("signed error") for each compound, labeled with its identification code 'id', was calculated as

$$
\begin{aligned}
\Delta_{\mathrm{id}} & =\log D_{c w, \mathrm{id}}^{\mathrm{exp}}-\log D_{c w, \mathrm{id}}, \\
\varepsilon_{\Delta, \mathrm{id}} & =\sqrt{\left(\varepsilon_{\mathrm{id}}^{\mathrm{exp}}\right)^{2}+\varepsilon_{\mathrm{id}}^{2}}
\end{aligned}
$$

with the uncertainty $\varepsilon_{\Delta}$ of $\Delta$ determined as the standard error from propagating the experimental and simulation errors (Eq. 6) through Eq. 7a

The root mean square error (RMSE) was determined from the individual errors $\Delta$ as

$$
\operatorname{RMSE}=\sqrt{\left\langle\Delta^{2}\right\rangle}=\sqrt{N^{-1} \sum_{\mathrm{id}}^{N} \Delta_{\mathrm{id}}^{2}},
$$

the absolute unsigned error (AUE) as

$$
\mathrm{AUE}=\langle|\Delta|\rangle=N^{-1} \sum_{\mathrm{id}}^{N}\left|\Delta_{\mathrm{id}}\right|,
$$

and the signed mean error (ME, also called the "mean signed error", MSE) as

$$
\mathrm{ME}=\langle\Delta\rangle=N^{-1} \sum_{\mathrm{id}}^{N} \Delta_{\mathrm{id}} .
$$


The standard errors of the RMSE, AUE, and ME were estimated via error propagation of the individual uncertainties Eq. $7 \mathrm{~b}$ through Eqs. 8 10 as

$$
\begin{aligned}
\varepsilon_{\mathrm{RMSE}} & =\frac{1}{N \mathrm{RMSE}} \sqrt{\sum_{\mathrm{id}}^{N} \Delta_{\mathrm{id}}^{2} \varepsilon_{\Delta, \mathrm{id}}^{2}}=\frac{1}{\sqrt{N}} \sqrt{\frac{\left\langle\left(\Delta \varepsilon_{\Delta}\right)^{2}\right\rangle}{\left\langle\Delta^{2}\right\rangle}}, \\
\varepsilon_{\mathrm{ME}} & =\varepsilon_{\mathrm{AUE}}=\frac{1}{\sqrt{N}} \sqrt{\left\langle\varepsilon_{\Delta}^{2}\right\rangle} .
\end{aligned}
$$

Eq. 11a followed the derivation of the root mean square error of prediction in Ref. [42] but remains more conservative by omitting a correction factor of $1 / \sqrt{2}$.

\section{Results and Discussion}

The SAMPL5 set consisted of challenging compounds that required the introduction of a number of new OPLS-AA atom types. The computed distribution coefficients generally differed systematically from the experimental values, without any clear, discernible pattern based on the chemical character of the compounds. We discuss potential sources for the observed systematic error.

\subsection{Validation of cyclohexane parameters}

Cyclohexane was parameterized with the standard OPLS-AA alkane parameters, following the original work [14]. The parameterization was validated by (1) computing the density as a function of temperature, (2) calculation of the chemical potential and (3) calculation of the hydration free energy and comparison to experimental values.

The bulk density of cyclohexane was calculated from simulations with 140 cyclohexane molecules (cubic simulation cell with length $3 \mathrm{~nm}$ ) of $100 \mathrm{~ns}$ length at temperatures from $273 \mathrm{~K}$ to $353 \mathrm{~K}$ and $P=1$ bar (Table 2). Experimental data from 228 experiments in the temperature range $273 \mathrm{~K}$ to $353 \mathrm{~K}$ were obtained from the Reaxys database and compared to the computed values (Figure 3). A few experimental data points and one computed value are below the melting point $(279.47 \mathrm{~K}$ [43]) and represent supercooled liquid; all reported values are below the boiling point (353.7 K [43]). Over the whole liquid range, the simulations slightly underestimate the density between $-1 \%$ at low temperatures and $-3.5 \%$ near the boiling point. At $T=300 \mathrm{~K}$, the error is $-2 \%$ but the computed density $0.7595 \pm 0.0001 \mathrm{~g} \cdot \mathrm{cm}^{-3}$ (standard error of the mean) is close to the density $0.755 \pm 0.001 \mathrm{~g} \cdot \mathrm{cm}^{-3}$ at $298 \mathrm{~K}$ that was reported for the original OPLS-AA parameterization [14]. Overall, the parameterization reproduces the density of cyclohexane satisfactorily.

The chemical potential of cyclohexane $\mu^{\text {cyclohexane }}$ is the transfer free energy of a cyclohexane molecule from vacuum to the pure cyclohexane solvent, $\Delta G_{c}^{\text {cyclohexane }}$. We calculated $\Delta G_{c}^{\text {cyclohexane }}$ with the FEP protocol described above. The computed value is $-4.00 \pm 0.06 \mathrm{kcal} / \mathrm{mol}$, which matches the experimental value $-4.43 \mathrm{kcal} / \mathrm{mol}$ [44] rather well. The hydration free energy of cyclohexane $\Delta G_{w}^{\text {cyclohexane }}$ was calculated in a similar way and the calculated value of $2.03 \pm 0.05 \mathrm{kcal} / \mathrm{mol}$ agrees fairly well ( $<1 \mathrm{kcal} / \mathrm{mol}$ error) with the experimental value $1.23 \pm 0.60 \mathrm{kcal} / \mathrm{mol}$ [44]. 
Table 2: Density of cyclohexane.

\begin{tabular}{ccrr}
\hline$T(\mathrm{~K})$ & $\rho_{\exp }\left(\mathrm{g} \cdot \mathrm{cm}^{-3}\right)^{\mathrm{a}} \rho_{\text {sim }}\left(\mathrm{g} \cdot \mathrm{cm}^{-3}\right)$ & rel.error \\
\hline 273 & 0.7967 & $0.7898(2)$ & $-0.9 \%$ \\
300 & $0.7737(1)$ & $0.7595(1)$ & $-1.9 \%$ \\
310 & $0.7636(1)$ & $0.7480(1)$ & $-2.2 \%$ \\
350 & 0.7241 & $0.7001(1)$ & $-3.5 \%$ \\
\hline
\end{tabular}

${ }^{\text {a }}$ Experimental densities were not available at the simulated temperature $T$ so we estimated the density as an average over experimental values within $T \pm 2 \mathrm{~K}$; the error indicates the spread over this range as half of the difference between larges and smalles value. When no error is given, only a single value was found in the range. ${ }^{b}$ Errors for simulated densities were estimated from a block average over five blocks of $20 \mathrm{~ns}$ length each and represent the standard error of the mean. $\quad{ }^{\mathrm{c}}$ The relative error to experiment was calculated as $\rho_{\text {sim }} / \rho_{\text {exp }}-1$.

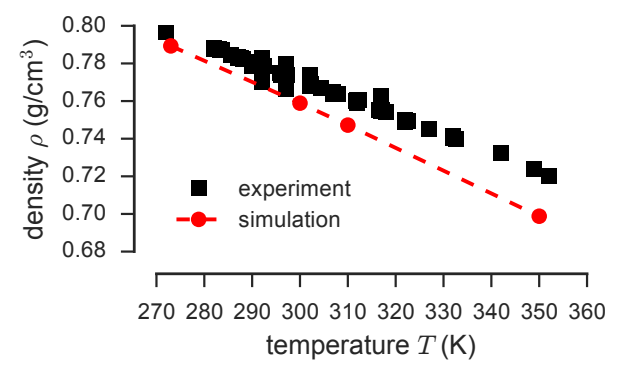

Fig. 3: Dependence of the density of cyclohexane on the temperature. Black squares are experimental data; red circles were computed from 100-ns MD simulations. The red dashed line was drawn to guide the eye.

Based on the good agreement of the calculated density and the free energies of solvation of cyclohexane in water and in cyclohexane with experimental values, we consider the cyclohexane parameters validated.

\subsection{Parameterization of new OPLS-AA atom types}

A number of compounds from the SAMPL5 data set required atom-types for several chemical groups that were absent from the OPLS-AA force field: $N$-substituted sulfamide (037), 2H-pyridazin-3-one (042), thiophene (002, 024, 033, 046 and 047), 1,2,4-triazine (068), 1,2,4-thiadiazole (059) and 1,3,4-thiadiazole (021) (Figure 2). We have generated these missing atom types using CM5 charges [45], following the recent work of Jorgensen and colleagues [32, 33] (Table 1). The availability of CM5 charges, derived from Hirshfeld charges, in the GAUSSIAN program [31] (starting 
with version 09 revision D.01) has considerably simplified the applicability of this new parametrization protocol.

We could only validate these parameters for thiophene, with simulations carried out on thiophene and 2-methyl-thiophene for which experimental values of hydration free energies are available $(-1.42$ and $-1.38 \mathrm{kcal} / \mathrm{mol}$, respectively) [46]. The computed values are provided in Table S2 (Electronic supplementary material), showing an error in the prediction of $-1.18 \mathrm{kcal} / \mathrm{mol}(N V T)$ and $-1.56 \mathrm{kcal} / \mathrm{mol}(N P T)$ for thiophene, and $-1.00 \mathrm{kcal} / \mathrm{mol}(N V T)$ and $-1.39 \mathrm{kcal} / \mathrm{mol}(N P T)$ for 2-methylthiophene. These relatively high values might be related to a systematic error that we suspect to be present in our predictions (see discussion below).

This protocol seems to give relatively good results, at least when the subset parameterized with CM5 charges is compared to the whole data set. As will be discussed in more detail below, the root mean squared error (RMSE) for the whole data set (in $N P T$ ) is $3.95 \pm 0.05$ (standard error of the RMSE) and the absolute unsigned error (AUE) is $3.49 \pm 0.05$ (Table 33. RMSE and AUE of $\log D_{c w}$ predicted for the CM5 subset were better than the whole data set with $3.33 \pm 0.10$ and $2.87 \pm 0.10$ (NPT conditions), respectively. Although a definitive conclusion cannot be drawn from this small subset of ten SAMPL5 compounds out of 53, the results are encouraging and CM5 charges appear to be a promising approach.

The SAMPL5 data set contained several compounds presenting heterocyclic systems with fused rings, for which no parameters were available in the OPLS-AA force field: thieno[2,3-b]pyridine (002), $1 H$-benzo[ $d]$ imidazole (006), benzo[ $d]$ thiazole $(020,044,045,048)$, imidazo[2,1- $b][1,3,4]$ thiadiazole $(021)$, thieno[2,3- $b]$ quinoline (024), thieno[2,3- $d]$ pyrimidine (046), pyrido $\left[2^{\prime}, 3^{\prime}: 3,4\right]$ pyrazolo $[1,5-a]$ pyrimidine (050), $9 H$-pyrido[3,4-b]indole (060). For all these heterocyclic systems we tentatively evaluated an original approach involving the use of force field parameters of the individual rings composing these systems. The charge of the 'bridgehead' atoms is obtained by summing the charges of the corresponding atoms in the individual rings, and those of the hydrogen atoms connected to them. The overall RMSE and AUE of $\log D_{c w}$ values predicted for these 11 compounds with non-parameterized fused-ring heterocyclic systems were $3.59 \pm 0.11$ and $3.09 \pm 0.10$ (NPT conditions), which are similar to those obtained for the ensemble of 53 compounds from the SAMPL5 data set (Table 3).

Finally, an analysis of the results obtained for compound 042 with two alternative aromatic and non-aromatic tautomeric forms shows that the non-aromatic $2 \mathrm{H}$ pyridazin-3-one form of the heterocycle gives better results than the aromatic 3hydroxy-pyridazine one (error in the $\log D_{c w}$ prediction of $-2.85 \pm 0.32$ and $-5.22 \pm$ 0.32 , respectively). These results are in agreement with the fact that the non-aromatic $2 \mathrm{H}$-pyridazin-3-one is the major form $(5.68 \mathrm{kcal} / \mathrm{mol}$ more stable than the aromatic 3-hydroxy-pyridazine, according to DFT calculations carried out at the M06-2X/6$311+\mathrm{G}(2 \mathrm{df}, 2 \mathrm{p}) / / \mathrm{B} 3 \mathrm{LYP} / 6-31 \mathrm{G}(\mathrm{d})$ level using GaUssian09 [31]), highlighting the importance of considering all representative forms of the compound of interest in the prediction of solvation free energies or distribution coefficients.

For the parameterization of compounds 005 and 092 we used the parameters of $\mathrm{N}$-methyl-imidazole that we generated in our previous work [12]. For these compounds we obtained errors in the $\log D_{c w}$ prediction of 0.17 and $-5.12(N P T)$, re- 


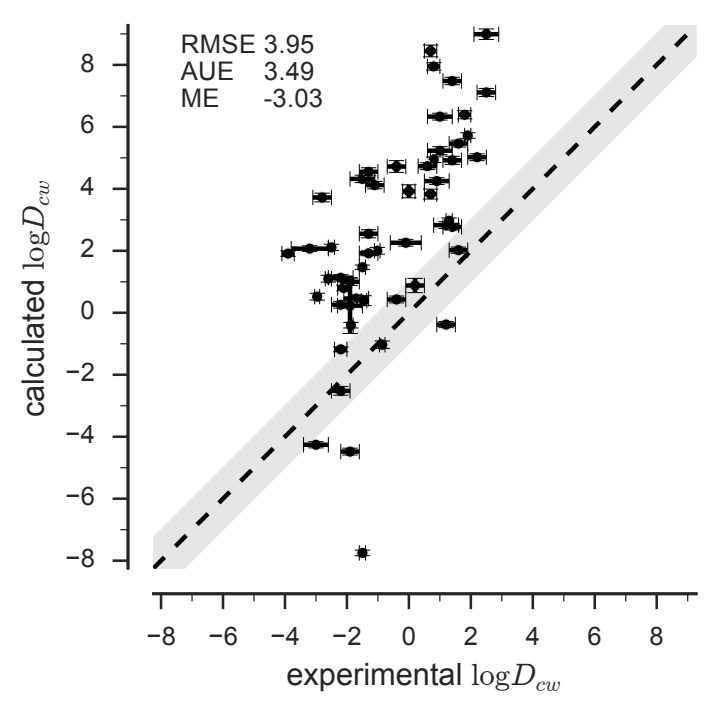

Fig. 4: Correlation between experimental and computed water-cyclohexane distribution coefficients $\log D_{c w}$ for simulations performed in the NPT ensemble. The gray band indicates $\pm 1 \log$-units from ideal correlation, shown by the dashed line. The root mean square error (RMSE), the absolute unsigned error (AUE), and the (signed) mean error (ME) are indicated. Error bars represent the error in the experiments or the error on the mean, derived from the simulations.

spectively. However, with only two compounds and such a spread in error, validation of the methyl-imidazole parameters by comparison to the $\log D_{c w}$ data is not feasible.

\subsection{Predicted distribution coefficients}

For each molecule, absolute solvation free energy calculations were carried out using topologies generated with standard OPLS-AA atom types and if necessary, the new parameters from Table 1. Calculations were performed in the NVT and NPT ensemble, with the values shown in Supplementary Table S1. A single compound from the SAMPL5 data set (080) has an experimental value of hydration free energy reported in literature $(-12.82 \pm 0.15 \mathrm{kcal} / \mathrm{mol})[5]$ and a comparison with the computed values shows an error in the prediction of $0.71 \mathrm{kcal} / \mathrm{mol}$ and $0.55 \mathrm{kcal} / \mathrm{mol}$ in $N V T$ and $N P T$, respectively.

From the solvation free energies, $\log D_{c w}$ were computed according to Eqs. 4 and 5. The distribution coefficients are tabulated in Table 3 . The accuracy of the computed distribution coefficients was quantified by computing the root mean square error (RMSE), the mean absolute unsigned error (AUE), and the mean error (ME) from the experimental values. 
Table 3: Computed $\left(\log D_{c w}\right)$ and experimental $\left(\log D_{c w}^{\exp }\right)$ water-cyclohexane distribution coefficients with error estimate for all SAMPL5 compounds. The difference $\Delta$ (Eq. 7a) between experimental and computed watercyclohexane distribution coefficients is shown for each compound. The standard error of the mean in the last significant digits is given in parentheses (Eq. 7b). The root mean square error (RMSE), the absolute unsigned error (AUE), and the signed mean error (ME) were calculated according to Eqs. 8

\begin{tabular}{|c|c|c|c|c|c|c|c|}
\hline \multirow[t]{2}{*}{ id } & \multirow{2}{*}{$\begin{array}{c}\text { Exp. } \\
\log D_{c w}^{\text {exp }}\end{array}$} & \multicolumn{2}{|c|}{ Protocol $N V T^{\mathrm{a}}$} & \multicolumn{2}{|c|}{ Protocol NPT } & \multirow{2}{*}{$\begin{array}{l}\text { Ligandbook } \\
\text { ID }^{\mathrm{b}}\end{array}$} & \multirow[t]{2}{*}{ Parameterization } \\
\hline & & $\log D_{c w}$ & $\Delta$ & $\log D_{c w}$ & $\Delta$ & & \\
\hline 002 & $1.40(30)$ & $3.14(11)$ & $-1.74(32)$ & $2.77(10)$ & $-1.37(32)$ & 2825 & \multirow[t]{13}{*}{ thiophene with CM5 } \\
\hline 003 & $1.90(10)$ & $5.71(09)$ & $-3.81(13)$ & $5.72(9)$ & $-3.82(13)$ & 2826 & \\
\hline 004 & $2.20(30)$ & $4.19(11)$ & $-1.99(32)$ & $5.02(11)$ & $-2.82(32)$ & 2827 & \\
\hline 005 & $-0.86(9)$ & $-1.41(13)$ & $0.55(16)$ & $-1.03(12)$ & $0.17(15)$ & 2828 & \\
\hline 006 & $-1.02(9)$ & $0.80(11)$ & $-1.82(14)$ & $2.00(11)$ & $-3.02(14)$ & 2829 & \\
\hline 007 & $1.40(30)$ & $3.85(11)$ & $-2.45(32)$ & $4.92(13)$ & $-3.52(33)$ & 2830 & \\
\hline 010 & $-1.70(40)$ & $-0.18(10)$ & $-1.52(41)$ & $0.46(11)$ & $-2.16(41)$ & 2831 & \\
\hline 011 & $-2.96(8)$ & $0.48(10)$ & $-3.44(13)$ & $0.52(11)$ & $-3.48(14)$ & 2832 & \\
\hline 013 & $-1.50(40)$ & $3.84(13)$ & $-5.34(42)$ & $4.32(12)$ & $-5.82(42)$ & 2833 & \\
\hline 015 & $-2.20(30)$ & $-0.17(12)$ & $-2.03(32)$ & $0.26(11)$ & $-2.46(32)$ & 2834 & \\
\hline 017 & $2.50(30)$ & $5.89(11)$ & $-3.39(32)$ & $7.11(13)$ & $-4.61(33)$ & 2835 & \\
\hline 019 & $1.20(40)$ & $2.09(11)$ & $-0.89(41)$ & $2.83(11)$ & $-1.63(41)$ & 2836 & \\
\hline 020 & $1.60(30)$ & $1.22(10)$ & $0.38(32)$ & $2.02(10)$ & $-0.42(32)$ & 2837 & \\
\hline 021 & $1.20(30)$ & $-0.35(09)$ & $1.55(31)$ & $-0.38(10)$ & $1.58(32)$ & 2838 & \multirow{4}{*}{$\begin{array}{l}\text { 1,3,4-thiadiazole with CM5 } \\
\text { thiophene with CM5 }\end{array}$} \\
\hline 024 & $1.00(40)$ & $5.05(13)$ & $-4.05(42)$ & $5.23(13)$ & $-4.23(42)$ & 2839 & \\
\hline 026 & $-2.60(10)$ & $0.26(10)$ & $-2.86(14)$ & $1.10(11)$ & $-3.70(15)$ & 2840 & \\
\hline 027 & $-1.87(7)$ & $-0.43(09)$ & $-1.44(11)$ & $-0.40(9)$ & $-1.47(11)$ & 2841 & \\
\hline 033 & $1.80(20)$ & $5.90(12)$ & $-4.10(23)$ & $6.39(13)$ & $-4.59(24)$ & 2842 & \multirow{5}{*}{$\begin{array}{l}\text { thiophene with CM5 } \\
\text { sulfamide with adapted sulfonamide } \\
\text { aromatic tautomer form of } \\
2 \mathrm{H} \text {-pyridazin-3-one, with pyridazine } \\
\text { parameters }\end{array}$} \\
\hline 037 & $-1.50(10)$ & $-7.58(11)$ & $6.08(15)$ & $-7.75(9)$ & $6.25(13)$ & 2843 & \\
\hline 042 & $-1.10(30)$ & $4.38(12)$ & $-5.48(32)$ & $4.12(12)$ & $-5.22(32)$ & 2845 & \\
\hline 044 & $1.00(40)$ & $5.75(11)$ & $-4.75(41)$ & $6.33(11)$ & $-5.33(41)$ & 2847 & \\
\hline 045 & $-2.10(20)$ & $0.00(9)$ & $-2.10(22)$ & $0.80(9)$ & $-2.90(22)$ & 2848 & \\
\hline 046 & $0.20(30)$ & $0.52(18)$ & $-0.32(35)$ & $0.88(23)$ & $-0.68(38)$ & 2849 & \multirow{8}{*}{$\begin{array}{l}\text { thiophene with CM5 } \\
\text { thiophene with CM5 }\end{array}$} \\
\hline 047 & $-0.40(30)$ & $-0.16(14)$ & $-0.24(33)$ & $0.43(11)$ & $-0.83(32)$ & 2850 & \\
\hline 048 & $0.90(40)$ & $3.55(11)$ & $-2.65(41)$ & $4.25(11)$ & $-3.35(41)$ & 2851 & \\
\hline 049 & $1.30(10)$ & $2.55(10)$ & $-1.25(14)$ & $2.97(9)$ & $-1.67(13)$ & 2852 & \\
\hline 050 & $-3.20(60)$ & $2.57(9)$ & $-5.77(61)$ & $2.07(9)$ & $-5.27(61)$ & 2853 & \\
\hline 055 & $-1.50(10)$ & $1.42(8)$ & $-2.92(13)$ & $1.47(7)$ & $-2.97(12)$ & 2854 & \\
\hline 056 & $-2.50(10)$ & $0.90(10)$ & $-3.40(14)$ & $2.11(10)$ & $-4.61(14)$ & 2855 & \\
\hline 058 & $0.80(10)$ & $4.66(9)$ & $-3.86(13)$ & 4.94(9) & $-4.14(13)$ & 2856 & \\
\hline 059 & $-1.30(30)$ & $1.47(8)$ & $-2.77(31)$ & $1.92(8)$ & $-3.22(31)$ & 2857 & \multirow[t]{6}{*}{ 1,2,4-thiadiazole with CM5 } \\
\hline 060 & $-3.90(20)$ & $1.64(9)$ & $-5.54(22)$ & 1.91(9) & $-5.81(22)$ & 2858 & \\
\hline 061 & $-1.45(9)$ & $-0.25(22)$ & $-1.20(24)$ & $0.39(16)$ & $-1.84(18)$ & 2859 & \\
\hline 063 & $-3.00(40)$ & $-5.04(10)$ & $2.04(41)$ & $-4.26(10)$ & $1.26(41)$ & 2860 & \\
\hline 065 & $0.70(20)$ & $8.17(18)$ & $-7.47(27)$ & $8.45(19)$ & $-7.75(28)$ & 2861 & \\
\hline 067 & $-1.30(30)$ & $3.27(13)$ & $-4.57(33)$ & $4.55(13)$ & $-5.85(33)$ & 2862 & \\
\hline 068 & $1.40(30)$ & $6.51(11)$ & $-5.11(32)$ & $7.48(12)$ & $-6.08(32)$ & 2863 & \multirow[t]{7}{*}{ 1,2,4-triazine with CM5 } \\
\hline 069 & $-1.30(30)$ & $2.12(12)$ & $-3.42(32)$ & $2.55(13)$ & $-3.85(33)$ & 2864 & \\
\hline 070 & $1.60(30)$ & $5.27(11)$ & $-3.67(32)$ & $5.46(11)$ & $-3.86(32)$ & 2865 & \\
\hline 071 & $-0.10(50)$ & $1.99(10)$ & $-2.09(51)$ & $2.26(11)$ & $-2.36(51)$ & 2866 & \\
\hline 072 & $0.60(30)$ & $4.44(12)$ & $-3.84(32)$ & $4.73(11)$ & $-4.13(32)$ & 2867 & \\
\hline 074 & $-1.90(30)$ & $-4.21(11)$ & $2.31(32)$ & $-4.48(11)$ & $2.58(32)$ & 2868 & \\
\hline 075 & $-2.80(30)$ & $2.65(14)$ & $-5.45(33)$ & $3.72(14)$ & $-6.52(33)$ & 2869 & \\
\hline 080 & $-2.20(20)$ & $-1.43(8)$ & $-0.77(22)$ & $-1.18(8)$ & $-1.02(22)$ & 2870 & \multirow[t]{3}{*}{ adapted purine and amide parameters } \\
\hline 081 & $-2.20(30)$ & $-2.50(11)$ & $0.30(32)$ & $-2.52(14)$ & $0.32(33)$ & 2871 & \\
\hline 082 & $2.50(40)$ & $8.52(14)$ & $-6.02(42)$ & $8.99(17)$ & $-6.49(43)$ & 2872 & \\
\hline 083 & $-1.90(40)$ & $-4.69(68)$ & $2.79(79)$ & $0.23(90)$ & $-2.13(98)$ & 2873 & \multirow[t]{2}{*}{ (1.5 ns equilibration MD) } \\
\hline 084 & $0.00(20)$ & $3.10(15)$ & $-3.10(25)$ & $3.92(21)$ & $-3.92(29)$ & 2874 & \\
\hline 085 & $-2.20(40)$ & $0.33(10)$ & $-2.53(41)$ & $1.13(10)$ & $-3.33(41)$ & 2875 & \multirow{5}{*}{$\begin{array}{l}\text { hydantoin with adapted urea and amide } \\
\text { parameters }\end{array}$} \\
\hline 086 & $0.70(20)$ & $2.89(19)$ & $-2.19(28)$ & $3.83(16)$ & $-3.13(26)$ & 2877 & \\
\hline 088 & $-1.90(30)$ & $0.15(12)$ & $-2.05(32)$ & $1.00(12)$ & $-2.90(32)$ & 2878 & \\
\hline 090 & $0.80(20)$ & $8.04(12)$ & $-7.24(23)$ & $7.95(12)$ & $-7.15(23)$ & 2879 & \\
\hline 092 & $-0.40(30)$ & $3.80(17$ & $-4.20(34)$ & $4.72(19)$ & $-5.12(36)$ & 2880 & \\
\hline \multicolumn{3}{|c|}{ RMS Error (RMSE) } & $3.56(5)$ & & $3.95(5)$ & & \\
\hline Absol & ute Unsigned & rror (AUE) & $3.07(5)$ & & $3.49(5)$ & & \\
\hline Mean & Error (ME) & & $-2.47(5)$ & & $-3.03(5)$ & & \\
\hline
\end{tabular}

a These results represent our first submission to SAMPL5 (\#68). $\quad{ }^{\mathrm{b}}$ Parameters for Gromacs (ITP and PDB files) were deposited in the Ligandbook repository https://ligandbook.org under this accession number. 
The RMSE was $3.95 \pm 0.05$ for the $N P T$ calculation; the RMSE for the NVT calculations was marginally better with $3.56 \pm 0.05$. The $N V T$ results had been submitted to the SAMPL5 challenge as entries \#68 (see Table 3) and \#32 (Table 4) and were analyzed by the SAMPL5 organizers in the context of all other submissions [47]. Nevertheless, in the following we primarily discuss the results from the NPT calculations because these values should in principle better represent the experimental measurements. Furthermore, NPT calculations also yielded good statistical reproducibility of the van der Waals component of the FEP calculations unlike $N V T$ calculations, which depended sensitively on the initial simulation system size [12]. The similar RMSE between the NVT and NPT simulations suggests that in a large data set, the $N V T$ van der Waals error averages out and the overall precision in prediction is similar, as indicated by a high degree of correlation between the $N V T$ and $N P T$ distribution coefficients as measured by the Pearson linear correlation coefficient $r=0.97$ (Figure S2 and discussion in the Electronic supplementary material).

The correlation between experimental and computed values in Figure 4 also showed a wide spread of values. Although a few compounds like 005, 020, 046, 047, and 081 were within one log unit, many others were off by three or more units, with a few as far as more than seven units (such as 065 and 090). The Pearson correlation coefficient $r$ for both the NPT and the NVT calculations was 0.64 (with $r=1$ indicating perfect correlation, 0 no correlation, and -1 perfect anticorrelation), summarizing the moderate success in quantitatively predicting $\log D_{c w}$. To quantify the ability to rank-order the data we computed the Kendall rank correlation coefficient $\tau$; a value of $\tau=1$ indicates that the simulations predict the same ranking of compounds by $\log D_{c w}$ as the experimental data whereas if the rankings were completely reversed $\tau$ would obtain the value -1 and if the simulations produced random results, a value close to 0 would be expected. The NPT data yielded $\tau=0.49$, slightly better than the value of 0.47 for the $N V T$ predictions. The simulations are moderately successful at rank-ordering compounds, with the NPT protocol being slightly better despite a worse RMSE.

For a number of compounds $(\mathbf{0 3 7}, \mathbf{0 4 2}, \mathbf{0 8 5})$ we also explored alternative parameterizations but without any clear improvements (Table 4). Compound $\mathbf{0 8 3}$ is a large and complicated macrocyle that is likely able to undergo slow conformational changes. Initially, we had only been able to sample for one tenth of the simulation time and obtained an error of $-2.13 \pm 0.98$ (1.5 ns instead of $15 \mathrm{~ns}$, see Table 3). However, neither more extensive sampling for $15 \mathrm{~ns}$ improved the prediction (error $-3.73 \pm 0.49$ ) nor alternative starting conformations with 15 ns sampling (error $-2.69 \pm 0.48$; see Table 4 .

The overall quality of the prediction is worse than one would have expected from the accuracy that is considered achievable for solvation free energy calculations (1$2 \mathrm{kcal} / \mathrm{mol}$ ), namely 1-2 $\log$ units at $T=300 \mathrm{~K}$ (estimated from Eq. 6). We did not detect an obvious pattern in the chemical character of the compounds that were predicted well versus the ones that were predicted poorly. However, visual inspection of the correlation plot (Figure 4) indicated that most predictions were too positive compared to the experimental values, which was also borne out by the (signed) mean error (ME) of $-3.03 \pm 0.05$ (calculated as experimental value minus computed value, 
Table 4: Computed $\left(\log D_{c w}\right)$ and experimental $\left(\log D_{c w}^{\exp }\right)$ water-cyclohexane distribution coefficients for selected SAMPL5 compounds with modified simulation parameters. The standard error of the mean in the last significant digits is given in parentheses. See Table 3 for further details.

\begin{tabular}{|c|c|c|c|c|c|c|c|}
\hline \multirow[t]{2}{*}{ id } & \multirow{2}{*}{$\begin{array}{c}\text { Exp. } \\
\log D_{c w}^{\exp }\end{array}$} & \multicolumn{2}{|c|}{ Protocol $N V T$} & \multicolumn{2}{|c|}{ Protocol NPT } & \multirow{2}{*}{$\begin{array}{l}\text { Ligandbook } \\
\text { ID }^{\mathrm{a}}\end{array}$} & \multirow[t]{2}{*}{ Parameterization } \\
\hline & & $\log D_{c w}$ & $\Delta$ & $\log D_{c w}$ & $\Delta$ & & \\
\hline 037 & $-1.50(10)$ & & & $-4.80(8)$ & $3.30(13)$ & 2844 & \multirow{4}{*}{$\begin{array}{l}\text { sulfamide with CM5 } \\
2 H \text {-pyridazin-3-one with CM5 } \\
\text { ( } 15 \text { ns equilibration MD) } \\
\text { ( } 15 \text { ns equilibration MD, alternative initial } \\
\text { conformation) }\end{array}$} \\
\hline 042 & $-1.10(30)$ & $2.27(11)^{b}$ & $-3.37(32)^{b}$ & $1.75(11)$ & $-2.85(32)$ & 2846 & \\
\hline 083 & $-1.90(40)$ & & & $1.83(28)$ & $-3.73(49)$ & 2873 & \\
\hline 083 & $-1.90(40)$ & & & $0.79(27)$ & $-2.69(48)$ & 2873 & \\
\hline 085 & $-2.20(40)$ & $1.52(10)^{b}$ & $-3.72(41)^{b}$ & $2.69(10)$ & $-4.89(41)$ & 2876 & hydantoin with adapted uracil parameters \\
\hline
\end{tabular}

${ }^{a}$ Parameters for Gromacs (ITP and PDB files) were deposited in the Ligandbook repository https://ligandbook.org under this accession number. $\quad \mathrm{b}$ These results were substituted for the computed values in Table 3 and the new data set comprised our second submission to SAMPL5 (\#32).

see Table 3 for details). Overall, these results suggested the presence of a systematic error.

If we were to assume that our results could be corrected by systematically shifting the calculated values by the ME then the shifted NPT data would have an RMSE of 2.55 instead of 3.95; the shifted $N V T$ data would have a similar RMSE of 2.57 instead of 3.56. Even if such an ad-hoc correction were to be considered, the resulting accuracy would remain modest.

It is therefore important to understand the source of the systematic error, with the hope to improve both the systematic shift and the low accuracy. Our previous SAMPL4 hydration free energy results [12] showed a systematically too positive $\Delta G_{w}$. We therefore hypothesize that primarily the hydration free energy calculations contribute to the systematic error in $\log D_{c w}$. However, the experimental distribution coefficient data do not contain sufficient information to distinguish our hypothesis from the other possibilities of either only $\Delta G_{c}$ being in error or both $\Delta G_{w}$ and $\Delta G_{c}$ contributing similarly. In addition to $\log D_{c w}$, either the experimental hydration free energies or the cyclohexane free energies would be required to directly test our hypothesis. Only for compound 080 (caffeine) hydration free energy data were available [5] and in this case, our prediction of $\log D_{c w}$ was already fairly good with an error of $-1.02 \pm 0.22$. To test our hypothesis, we began to compile an alternative test data set of 92 compounds with known $\Delta G_{w}$ and $\Delta G_{c}$ and calculated the solvation free energies (manuscript in preparation). Preliminary results indicated that for this data set, the cyclohexane solvation free energy can be accurately computed with an RMSE less than $0.8 \mathrm{kcal} / \mathrm{mol}$. The hydration free energy $\Delta G_{w}$, however, was more difficult to compute (RMSE $1.5 \mathrm{kcal} / \mathrm{mol}$ ) and was systematically overestimated, in agreement with our previous study [12]. Among the different water models that were evaluated in our preliminary study, TIP3P and SPC provided slightly better predictions than TIP4P, in agreement with the results of a previous report that calculated hydration free energies of amino acid analogues in the OPLS-AA force field with different water models [48]. It follows from Eq. 1] that a more positive $\Delta G_{w}$ leads to a more positive $\log D_{c w}$ and thus our hypothesis is consistent with the results shown here. Taken 
together, these results already suggest that the hydration free energy calculations are currently the major source of error in our distribution coefficient calculations.

\section{Conclusions}

We used explicit solvent all-atom MD simulations with the OPLS-AA force field and the TIP4P water model to predict water-cyclohexane distribution coefficients for the 53 compounds included in the SAMPL5 challenge. We validated cyclohexane parameters for the necessary cyclohexane solvation free energy calculations and introduced a number of new OPLS-AA atom types that were necessary to cover the chemical functionalities in the SAMPL5 compounds. The overall quality of our prediction was worse than expected from what should be theoretically possible with current stateof-the-art absolute solvation free energy calculations. Across the data set, there was no statistical difference between calculations in the $N V T$ and the NPT ensemble. Changes in parameterizations that were tested for a subset of compounds also did not make a difference and the errors did not seem to correspond to any specific chemical functional groups. An overall systematic error was observed whereby predicted distribution coefficients were too positive. Experimental distribution coefficients on their own were not sufficient to determine the source of the error. Based on calculations for an alternative test set of compounds (manuscript in preparation) we hypothesize that the hydration free energy calculations are the main source of the error and future work will focus on addressing this shortcoming in our OPLS-AA parameterization approach, including a critical assessment of the role of the water model itself.

\section{References}

1. Leeson PD, Springthorpe B (2007) The influence of drug-like concepts on decision-making in medicinal chemistry. Nat Rev Drug Discov 6(11):881-90, DOI 10.1038/nrd2445

2. Bannan CC, Calabro G, Kyu DY, Mobley DL (2016) Calculating partition coefficients of small molecules in octanol/water and cyclohexane/water. J Chem Theory Comput DOI 10.1021/acs.jctc.6b00449

3. Nicholls A, Mobley DL, Guthrie JP, Chodera JD, Bayly CI, Cooper MD, Pande VS (2008) Predicting small-molecule solvation free energies: An informal blind test for computational chemistry. J Med Chem 51(4):769-779, DOI 10.1021/jm070549+

4. Guthrie JP (2009) A blind challenge for computational solvation free energies: Introduction and overview. J Phys Chem B 113(14):4501-4507, DOI 10.1021/jp806724u

5. Geballe MT, Skillman AG, Nicholls A, Guthrie JP, Taylor PJ (2010) The SAMPL2 blind prediction challenge: Introduction and overview. J Comput Aided Mol Des 24(4):259-279, DOI 10.1007/s10822-010-9350-8

6. Geballe MT, Guthrie JP (2012) The SAMPL3 blind prediction challenge: transfer energy overview. J Comput Aided Mol Des 26(5):489-96, DOI 10.1007/s10822012-9568-8 
7. Mobley DL, Wymer KL, Lim NM, Guthrie JP (2014) Blind prediction of solvation free energies from the SAMPL4 challenge. J Comput Aided Mol Des 28(3):135-50, DOI 10.1007/s10822-014-9718-2

8. Rustenburg AS, Dancer J, Lin B, Ortwine DF, Mobley DL, Chodera JD (2016) Measuring experimental cyclohexane/water distribution coefficients for the SAMPL5 challenge. J Comput Aided Mol Des

9. Lin B, Pease JH (2013) A novel method for high throughput lipophilicity determination by microscale shake flask and liquid chromatography tandem mass spectrometry. Comb Chem High Throughput Screen 16(10):817-25, DOI $10.1021 / \mathrm{ct} 200866 \mathrm{~d}$

10. Jorgensen WL, Tirado-Rives J (2005) Potential energy functions for atomic-level simulations of water and organic and biomolecular systems. Proc Natl Acad Sci USA 102(19):6665-6670, DOI 10.1073/pnas.0408037102

11. Beckstein O, Iorga BI (2012) Prediction of hydration free energies for aliphatic and aromatic chloro derivatives using molecular dynamics simulations with the OPLS-AA force field. J Comput Aided Mol Des 26(5):635-645, DOI 10.1007/s10822-011-9527-9

12. Beckstein O, Fourrier A, Iorga BI (2014) Prediction of hydration free energies for the SAMPL4 diverse set of compounds using molecular dynamics simulations with the OPLS-AA force field. J Comput Aided Mol Des 28(3):265-276, DOI 10.1007/s10822-014-9727-1

13. Kaminski G, Duffy E, Matsui T, Jorgensen W (1994) Free energies of hydration and pure liquid properties of hydrocarbons from the OPLS all-atom model. J Phys Chem 98(49):13,077-13,082, DOI 10.1021/j100100a043

14. Jorgensen WL, Maxwell DS, Tirado-Rives J (1996) Development and testing of the OPLS all-atom force field on conformational energetics and properties of organic liquids. J Am Chem Soc 118(45):11,225-11,236, DOI 10.1021/ja9621760

15. Damm W, Frontera A, Tirado-Rives J, Jorgensen W (1997) OPLS allatom force field for carbohydrates. J Comput Chem 18(16):1955-1970, DOI 10.1002/(SICI)1096-987X(199712)18:16<1955::AID-JCC1>3.0.CO;2-L

16. Jorgensen WL, McDonald NA (1998) Development of an all-atom force field for heterocycles. Properties of liquid pyridine and diazenes. J Mol Struct THEOCHEM 424(1-2):145-155, DOI 10.1016/S0166-1280(97)00237-6

17. McDonald NA, Jorgensen WL (1998) Development of an all-atom force field for heterocycles. Properties of liquid pyrrole, furan, diazoles, and oxazoles. J Phys Chem B 102(41):8049-8059, DOI 10.1021/jp981200o

18. Rizzo RC, Jorgensen WL (1999) OPLS all-atom model for amines: Resolution of the amine hydration problem. J Am Chem Soc 121(20):4827-4836, DOI $10.1021 / \mathrm{ja} 984106 \mathrm{u}$

19. Kaminski GA, Friesner RA, Tirado-Rives J, Jorgensen WL (2001) Evaluation and reparametrization of the OPLS-AA force field for proteins via comparison with accurate quantum chemical calculations on peptides. J Phys Chem B 105(28):6474-6487, DOI 10.1021/jp003919d

20. Hess B, Kutzner C, van der Spoel D, Lindahl E (2008) GROMACS 4: Algorithms for highly efficient, load-balanced, and scalable molecular simulation. J Chem Theory Comput 4(3):435-447, DOI 10.1021/ct700301q 
21. Pronk S, Páll S, Schulz R, Larsson P, Bjelkmar P, Apostolov R, Shirts MR, Smith JC, Kasson PM, van der Spoel D, Hess B, Lindahl E (2013) GROMACS 4.5: a high-throughput and highly parallel open source molecular simulation toolkit. Bioinformatics 29(7):845-54, DOI 10.1093/bioinformatics/btt055

22. Watkins EK, Jorgensen WL (2001) Perfluoroalkanes: Conformational analysis and liquid-state properties from ab initio and Monte Carlo calculations. J Phys Chem A 105(16):4118-4125, DOI 10.1021/jp004071w

23. Price M, Ostrovsky D, Jorgensen W (2001) Gas-phase and liquid-state properties of esters, nitriles, and nitro compounds with the OPLS-AA force field. J Comput Chem 22(13):1340-1352, DOI 10.1002/jcc.1092

24. Kony D, Damm W, Stoll S, Van Gunsteren W (2002) An improved OPLSAA force field for carbohydrates. J Comput Chem 23(15):1416-1429, DOI $10.1002 /$ jcc. 10139

25. Kahn K, Bruice T (2002) Parameterization of OPLS-AA force field for the conformational analysis of macrocyclic polyketides. J Comput Chem 23(10):977996, DOI 10.1002/jcc.10051

26. Thomas L, Christakis T, Jorgensen W (2006) Conformation of alkanes in the gas phase and pure liquids. J Phys Chem B 110(42):21,198-21,204, DOI 10.1021/jp064811m

27. Jorgensen W, Jensen K, Alexandrova A (2007) Polarization effects for hydrogenbonded complexes of substituted phenols with water and chloride ion. J Chem Theory Comput 3(6):1987-1992, DOI 10.1021/ct7001754

28. Xu Z, Luo HH, Tieleman DP (2007) Modifying the OPLS-AA force field to improve hydration free energies for several amino acid side chains using new atomic charges and an off-plane charge model for aromatic residues. J Comput Chem 28(3):689-697, DOI 10.1002/jcc.20560

29. Domański J, Beckstein O, Iorga BI (2012) Ligandbook - an online repository for small and drug-like molecule force field parameters. In: 244th Meeting of the American Chemical Society - Abstracts of Papers, pp 227-COMP, URL https : //ligandbook.org

30. Jorgensen WL, Chandrasekhar J, Madura JD, Impey RW, Klein ML (1983) Comparison of simple potential functions for simulating liquid water. $\mathrm{J}$ Chem Phys 79(2):926-935, DOI 10.1063/1.445869

31. Frisch MJ, Trucks GW, Schlegel HB, Scuseria GE, Robb MA, Cheeseman JR, Scalmani G, Barone V, Mennucci B, Petersson GA, Nakatsuji H, Caricato M, Li X, Hratchian HP, Izmaylov AF, Bloino J, Zheng G, Sonnenberg JL, Hada M, Ehara M, Toyota K, Fukuda R, Hasegawa J, Ishida M, Nakajima T, Honda Y, Kitao O, Nakai H, Vreven T, Montgomery JA Jr, Peralta JE, Ogliaro F, Bearpark M, Heyd JJ, Brothers E, Kudin KN, Staroverov VN, Kobayashi R, Normand J, Raghavachari K, Rendell A, Burant JC, Iyengar SS, Tomasi J, Cossi M, Rega N, Millam JM, Klene M, Knox JE, Cross JB, Bakken V, Adamo C, Jaramillo J, Gomperts R, Stratmann RE, Yazyev O, Austin AJ, Cammi R, Pomelli C, Ochterski JW, Martin RL, Morokuma K, Zakrzewski VG, Voth GA, Salvador P, Dannenberg JJ, Dapprich S, Daniels AD, Farkas O, Foresman JB, Ortiz JV, Cioslowski J, Fox DJ (2009) Gaussian 09 Revision D.01. Gaussian Inc. Wallingford CT 
32. Vilseck JZ, Tirado-Rives J, Jorgensen WL (2014) Evaluation of CM5 charges for condensed-phase modeling. J Chem Theory Comput 10(7):2802-2812, DOI $10.1021 / \mathrm{ct} 500016 \mathrm{~d}$

33. Dodda LS, Vilseck JZ, Cutrona KJ, Jorgensen WL (2015) Evaluation of CM5 charges for nonaqueous condensed-phase modeling. J Chem Theory Comput 11(9):4273-82, DOI 10.1021/acs.jctc.5b00414

34. Páll S, Abraham MJ, Kutzner C, Hess B, Lindahl E (2015) Tackling exascale software challenges in molecular dynamics simulations with GROMACS. In: Markidis S, Laure E (eds) Solving Software Challenges for Exascale: International Conference on Exascale Applications and Software, EASC 2014, Stockholm, Sweden, April 2-3, 2014, Revised Selected Papers, Lecture Notes in Computer Science, vol 8759, Springer International Publishing, Switzerland, pp 3-27, DOI 10.1007/978-3-319-15976-8_1

35. Mobley DL, Dumont E, Chodera JD, Dill KA (2007) Comparison of charge models for fixed-charge force fields: Small-molecule hydration free energies in explicit solvent. J Phys Chem B 111(9):2242-2254, DOI 10.1021/jp0667442

36. Parrinello M, Rahman A (1981) Polymorphic transitions in single crystals: A new molecular dynamics method. J Appl Phys 52(12):7182-7190, DOI 10.1063/1.328693, URL http://link. aip.org/link/?JAP/52/7182/1

37. Shirts MR, Pitera JW, Swope WC, Pande VS (2003) Extremely precise free energy calculations of amino acid side chain analogs: Comparison of common molecular mechanics force fields for proteins. J Chem Phys 119(11):5740-5761, DOI 10.1063/1.1587119

38. Essman U, Perela L, Berkowitz ML, Darden T, Lee H, Pedersen LG (1995) A smooth particle mesh Ewald method. J Chem Phys 103:8577-8592, DOI $10.1063 / 1.470117$

39. Hess B (2008) P-LINCS: A parallel linear constraint solver for molecular simulation. J Chem Theory Comput 4(1):116-122, DOI 10.1021/ct700200b

40. Jorge M, Garrido N, Queimada A, Economou I, Macedo E (2010) Effect of the integration method on the accuracy and computational efficiency of free energy calculations using thermodynamic integration. J Chem Theory Comput 6(4):1018-1027, DOI 10.1021/ct900661c

41. Jones E, Oliphant T, Peterson P, et al (2001-) SciPy: Open source scientific tools for Python. URL http://www . scipy.org/, [Online; accessed 2016-06-11]

42. Faber NKM (1999) Estimating the uncertainty in estimates of root mean square error of prediction: application to determining the size of an adequate test set in multivariate calibration. Chemometrics and Intelligent Laboratory Systems 49(1):79 - 89, DOI 10.1016/S0169-7439(99)00027-1

43. O'Neil MJ (ed) (2013) The Merck Index - An Encyclopedia of Chemicals, Drugs, and Biologicals. Royal Society of Chemistry, Cambridge, UK

44. Marenich AV, Kelly CP, Thompson JD, Hawkins GD, Chambers CC, Giesen DJ, Winget P, Cramer CJ, Truhlar DG (2009) Minnesota Solvation Database - version 2009, University of Minnesota, Minneapolis. URL http://comp.chem. umn . edu/mnsol/

45. Marenich AV, Jerome SV, Cramer CJ, Truhlar DG (2012) Charge Model 5: An extension of Hirshfeld population analysis for the accurate description of molec- 
ular interactions in gaseous and condensed phases. J Chem Theory Comput 8(2):527-41, DOI 10.1021/ct200866d

46. Mobley DL, Bayly CI, Cooper MD, Shirts MR, Dill KA (2009) Small molecule hydration free energies in explicit solvent: An extensive test of fixed-charge atomistic simulations. J Chem Theory Comput 5(2):350-358, DOI 10.1021/ct800409d

47. Bannan CC, Burley KH, Mobley DL (2016) Blind prediction of cyclohexanewater distribution coefficients from the SAMPL5 challenge. J Comput Aided Mol Des

48. Shirts MR, Pande VS (2005) Solvation free energies of amino acid side chain analogs for common molecular mechanics water models. J Chem Phys 122(13):134,508, DOI 10.1063/1.1877132 


\title{
Electronic supplementary material
}

Prediction of cyclohexane-water distribution coefficients for the SAMPL5 data set using molecular dynamics simulations with the OPLS-AA force field

\author{
Ian M. Kenney · Oliver Beckstein · Bogdan I. \\ Iorga
}

\section{Solvation free energies}

Solvation free energies $\Delta G_{\text {solv }}$ in water and cyclohexane for all SAMPL5 components reported in this study are listed in Table $\mathrm{S} 1$. Hydration free energies for model compounds used for parameterization are reported in Table $\mathbf{S 2}$. Parameters for Gromacs (ITP and PDB files) were deposited in the Ligandbook repository https: //ligandbook.org under the accession number give in the tables.

OB was supported in part by grant ACI-1443054 from the National Science Foundation. BII was supported in part by grants ANR-10-LABX-33 (LabEx LERMIT) and ANR-14-JAMR-0002-03 (JPIAMR) from the French National Research Agency (ANR).

I. M. Kenney

Department of Physics, Arizona State University, P.O. Box 871504, Tempe, AZ 85287-1504, USA

O. Beckstein

Department of Physics and Center for Biological Physics, Arizona State University, P.O. Box 871504, Tempe, AZ 85287-1504, USA

Tel.: +1 4807279765

Fax: $+1480965-4669$

E-mail: oliver.beckstein@asu.edu

B. I. Iorga

Institut de Chimie des Substances Naturelles, CNRS UPR 2301, Université Paris-Saclay, Labex LERMIT, 1 Avenue de la Terrasse, 91198 Gif-sur-Yvette, France

Tel.: +33169823094

Fax: +3316907 7247

E-mail: bogdan.iorga@cnrs.fr 
Table S1: Solvation free energies $\Delta G_{\text {solv }}\left(\mathrm{kcal} \cdot \mathrm{mol}^{-1}\right)$ from all SAMPL5 simulations reported in this study. The standard error of the mean in the last significant digits is given in parentheses. Parameters for Gromacs (ITP and PDB files) were deposited in the Ligandbook repository https://ligandbook. org under the ID accession number.

\begin{tabular}{|c|c|c|c|c|c|c|}
\hline \multirow[b]{2}{*}{ id } & \multicolumn{2}{|c|}{ water } & \multicolumn{2}{|c|}{ cyclohexane } & \multirow[b]{2}{*}{$\mathrm{ID}^{\mathrm{a}}$} & \multirow[b]{2}{*}{ Parameterization } \\
\hline & $N V T$ & $N P T$ & $N V T$ & $N P T$ & & \\
\hline 002 & $-10.23(11)$ & $-10.16(10)$ & $-14.54(10)$ & $-13.96(10)$ & 2825 & \\
\hline 003 & $-6.03(9)$ & $-5.70(9)$ & $-13.86(9)$ & $-13.54(9)$ & 2826 & \\
\hline 004 & $-9.65(10)$ & $-8.53(11)$ & $-15.40(12)$ & $-15.41(11)$ & 2827 & \\
\hline 005 & $-18.69(15)$ & $-18.15(13)$ & $-16.76(10)$ & $-16.74(11)$ & 2828 & \\
\hline 006 & $-10.15(10)$ & $-8.92(11)$ & $-11.24(11)$ & $-11.67(11)$ & 2829 & \\
\hline 007 & $-11.00(10)$ & $-9.30(13)$ & $-16.28(11)$ & $-16.06(12)$ & 2830 & \\
\hline 010 & $-13.44(10)$ & $-12.72(10)$ & $-13.19(9)$ & $-13.35(12)$ & 2831 & \\
\hline 011 & $-13.73(10)$ & $-13.49(10)$ & $-14.39(9)$ & $-14.21(11)$ & 2832 & \\
\hline 013 & $-15.67(12)$ & $-14.99(11)$ & $-20.93(13)$ & $-20.92(12)$ & 2833 & \\
\hline 015 & $-13.11(13)$ & $-12.53(13)$ & $-12.88(9)$ & $-12.89(8)$ & 2834 & \\
\hline 017 & $-8.78(11)$ & $-6.92(13)$ & $-16.87(12)$ & $-16.67(12)$ & 2835 & \\
\hline 019 & $-13.50(11)$ & $-12.51(11)$ & $-16.36(11)$ & $-16.39(12)$ & 2836 & \\
\hline 020 & $-12.64(10)$ & $-11.73(10)$ & $-14.31(10)$ & $-14.50(10)$ & 2837 & \\
\hline 021 & $-14.67(9)$ & $-14.41(9)$ & $-14.19(9)$ & $-13.88(10)$ & 2838 & 1,3,4-thiadiazole with CM5 \\
\hline 024 & $-13.05(12)$ & $-12.74(11)$ & $-19.99(13)$ & $-19.91(14)$ & 2839 & thiophene with CM5 \\
\hline 026 & $-11.33(10)$ & $-10.15(12)$ & $-11.69(9)$ & $-11.66(9)$ & 2840 & \\
\hline 027 & $-13.30(9)$ & $-13.04(8)$ & $-12.70(8)$ & $-12.49(8)$ & 2841 & \\
\hline 033 & $-9.96(11)$ & $-8.86(12)$ & $-18.05(12)$ & $-17.63(14)$ & 2842 & thiophene with CM5 \\
\hline 037 & $-19.89(11)$ & $-20.11(9)$ & $-9.49(9)$ & $-9.48(8)$ & 2843 & $\begin{array}{l}\text { sulfamide with adapted } \\
\text { sulfonamide }\end{array}$ \\
\hline 042 & $-11.40(12)$ & $-11.21(11)$ & $-17.42(11)$ & $-16.86(11)$ & 2845 & $\begin{array}{l}\text { aromatic tautomer form of } \\
2 \mathrm{H} \text {-pyridazin-3-one, with } \\
\text { pyridazine parameters }\end{array}$ \\
\hline 044 & $-11.68(11)$ & $-10.88(11)$ & $-19.57(11)$ & $-19.56(11)$ & 2847 & \\
\hline 045 & $-11.88(9)$ & $-10.74(9)$ & $-11.88(8)$ & $-11.83(9)$ & 2848 & \\
\hline 046 & $-17.00(23)$ & $-16.03(30)$ & $-17.72(11)$ & $-17.24(12)$ & 2849 & thiophene with CM5 \\
\hline 047 & $-14.99(16)$ & $-14.04(11)$ & $-14.78(10)$ & $-14.63(11)$ & 2850 & thiophene with CM5 \\
\hline 048 & $-13.77(11)$ & $-12.98(11)$ & $-18.65(11)$ & $-18.82(11)$ & 2851 & \\
\hline 049 & $-10.19(9)$ & $-9.35(9)$ & $-13.69(10)$ & $-13.43(10)$ & 2852 & \\
\hline 050 & $-9.69(9)$ & $-10.16(9)$ & $-13.22(9)$ & $-13.00(8)$ & 2853 & \\
\hline 055 & $-9.27(8)$ & $-8.85(7)$ & $-11.21(8)$ & $-10.87(7)$ & 2854 & \\
\hline 056 & $-10.44(10)$ & $-8.85(10)$ & $-11.68(10)$ & $-11.74(11)$ & 2855 & \\
\hline 058 & $-7.93(8)$ & $-6.95(8)$ & $-14.32(9)$ & $-13.72(10)$ & 2856 & \\
\hline 059 & $-8.04(8)$ & $-7.23(7)$ & $-10.06(8)$ & $-9.86(7)$ & 2857 & 1,2,4-thiadiazole with CM5 \\
\hline 060 & $-10.82(8)$ & $-10.20(9)$ & $-13.07(8)$ & $-12.81(9)$ & 2858 & \\
\hline 061 & $-10.41(29)$ & $-9.36(20)$ & $-10.07(8)$ & $-9.89(9)$ & 2859 & \\
\hline
\end{tabular}


Table S1 - continued

\begin{tabular}{|c|c|c|c|c|c|c|}
\hline \multirow[b]{2}{*}{ id } & \multicolumn{2}{|c|}{ water } & \multicolumn{2}{|c|}{ cyclohexane } & \multirow[b]{2}{*}{$\mathrm{ID}^{\mathrm{a}}$} & \multirow[b]{2}{*}{ Parameterization } \\
\hline & $N V T$ & $N P T$ & $N V T$ & $N P T$ & & \\
\hline 063 & $-18.09(11)$ & $-16.78(10)$ & $-11.17(9)$ & $-10.94(10)$ & 2860 & \\
\hline 065 & $-18.43(16)$ & $-17.32(18)$ & $-29.64(19)$ & $-28.92(18)$ & 2861 & \\
\hline 067 & $-8.87(15)$ & $-6.60(15)$ & $-13.36(10)$ & $-12.85(11)$ & 2862 & \\
\hline 068 & $-9.20(11)$ & $-7.82(11)$ & $-18.13(11)$ & $-18.08(12)$ & 2863 & 1,2,4-triazine with CM5 \\
\hline 069 & $-13.11(12)$ & $-12.33(13)$ & $-16.01(11)$ & $-15.83(11)$ & 2864 & \\
\hline 070 & $-6.89(11)$ & $-6.15(11)$ & $-14.13(11)$ & $-13.64(11)$ & 2865 & \\
\hline 071 & $-10.07(10)$ & $-9.15(10)$ & $-12.80(9)$ & $-12.26(11)$ & 2866 & \\
\hline 072 & $-5.72(13)$ & $-5.38(11)$ & $-11.81(11)$ & $-11.87(10)$ & 2867 & \\
\hline 074 & $-21.26(11)$ & $-21.25(11)$ & $-15.49(9)$ & $-15.10(10)$ & 2868 & \\
\hline 075 & $-9.00(17)$ & $-7.74(16)$ & $-12.65(10)$ & $-12.84(11)$ & 2869 & \\
\hline 080 & $-13.53(8)$ & $-13.37(8)$ & $-11.57(8)$ & $-11.75(7)$ & 2870 & $\begin{array}{l}\text { adapted purine and amide } \\
\text { parameters }\end{array}$ \\
\hline 081 & $-16.71(11)$ & $-17.23(15)$ & $-13.28(10)$ & $-13.77(11)$ & 2871 & \\
\hline 082 & $-5.66(13)$ & $-4.38(19)$ & $-17.35(14)$ & $-16.71(13)$ & 2872 & \\
\hline 083 & $-41.18(72)$ & $-34.96(88)$ & $-34.75(60)$ & $-35.28(87)$ & 2873 & (1.5 ns equilibration MD) \\
\hline 084 & $-13.29(17)$ & $-12.33(25)$ & $-17.54(13)$ & $-17.71(13)$ & 2874 & \\
\hline 085 & $-14.25(9)$ & $-13.24(10)$ & $-14.70(9)$ & $-14.79(10)$ & 2875 & $\begin{array}{l}\text { hydantoin with adapted urea } \\
\text { and amide parameters }\end{array}$ \\
\hline 086 & $-14.52(23)$ & $-12.76(18)$ & $-18.49(13)$ & $-18.02(12)$ & 2877 & \\
\hline 088 & $-13.55(11)$ & $-11.99(12)$ & $-13.75(12)$ & $-13.36(12)$ & 2878 & \\
\hline 090 & $-8.01(11)$ & $-7.07(12)$ & $-19.05(12)$ & $-17.98(11)$ & 2879 & \\
\hline 092 & $-21.52(16)$ & $-19.84(20)$ & $-26.73(16)$ & $-26.32(16)$ & 2880 & \\
\hline 037 & & $-16.16(8)$ & & $-9.57(8)$ & 2844 & sulfamide with CM5 \\
\hline 042 & $-15.64(11)$ & $-16.05(12)$ & $-18.75(11)$ & $-18.45(10)$ & 2846 & $\begin{array}{l}\text { 2H-pyridazin-3-one with } \\
\text { CM5 }\end{array}$ \\
\hline 083 & & $-31.51(25)$ & & $-34.02(28)$ & 2873 & $\begin{array}{l}\text { (15 ns equilibrium MD) } \\
\text { (15 ns equilibrium } \mathrm{MD} \text {, }\end{array}$ \\
\hline 083 & & $-31.78(29)$ & & $-32.86(22)$ & 2873 & $\begin{array}{l}\text { alternative initial } \\
\text { conformation) }\end{array}$ \\
\hline 085 & $-12.41(10)$ & $-11.08(10)$ & $-14.49(11)$ & $-14.77(10)$ & 2876 & $\begin{array}{l}\text { hydantoin with adapted } \\
\text { uracil parameters }\end{array}$ \\
\hline
\end{tabular}

${ }^{a}$ Parameters for Gromacs (ITP and PDB files) were deposited in the Ligandbook repository https://ligandbook.org under this accession number. 
Table S2 Hydration free energies $\Delta G_{\mathrm{hyd}}\left(\mathrm{kcal} \cdot \mathrm{mol}^{-1}\right)$ for compounds used for the validation of thiophene parameterization. In all cases, parameterization of thiophene rings used CM5 charges. The standard error of the mean in the last significant digits is given in parentheses.

\begin{tabular}{rccc}
\hline id & $N V T$ & $N P T$ & ID $^{\mathrm{a}}$ \\
\hline thiophene & $-0.24(4)$ & $0.14(5)$ & 2881 \\
2-Me-thiophene & $-0.38(5)$ & $0.01(5)$ & 2882 \\
\hline
\end{tabular}

${ }^{\text {a }}$ Parameters for Gromacs (ITP and PDB files) were deposited in the Ligandbook repository https://ligandbook.org under this accession number.

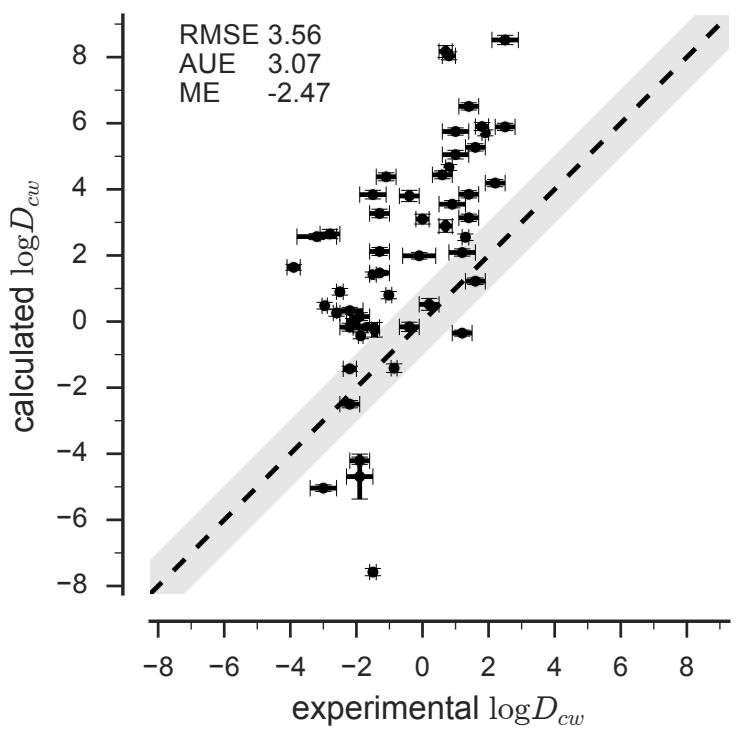

Fig. S1 Correlation between experimental and computed water-cyclohexane distribution coefficients $\log D_{c w}$ for simulations performed in the $N V T$ ensemble. The gray band indicates $\pm 1 \log$-units from ideal correlation, shown by the dashed line. The root mean square error (RMSE), the absolute unsigned error (AUE), and the (signed) mean error (ME) are indicated. Error bars represent the error in the experiments or the error on the mean, derived from the simulations.

\section{$2 \log D_{c w}$ correlations}

Figure $\mathrm{S} 1$ shows the correlation of the $\log D_{c w}$ computed in the $N V T$ ensemble to the experimental ones. The Pearson correlation coefficient is $r=0.64$ and the Kendall rank ordering coefficient is $\tau=0.47$.

In general, the distribution coefficients calculated in the NVT and NPT ensemble are highly correlated (Figure $\mathrm{S} 2$ ) with a Pearson correlation coefficient $r=0.97$. The two data sets also rank order almost all compounds in the same way as indicated by 


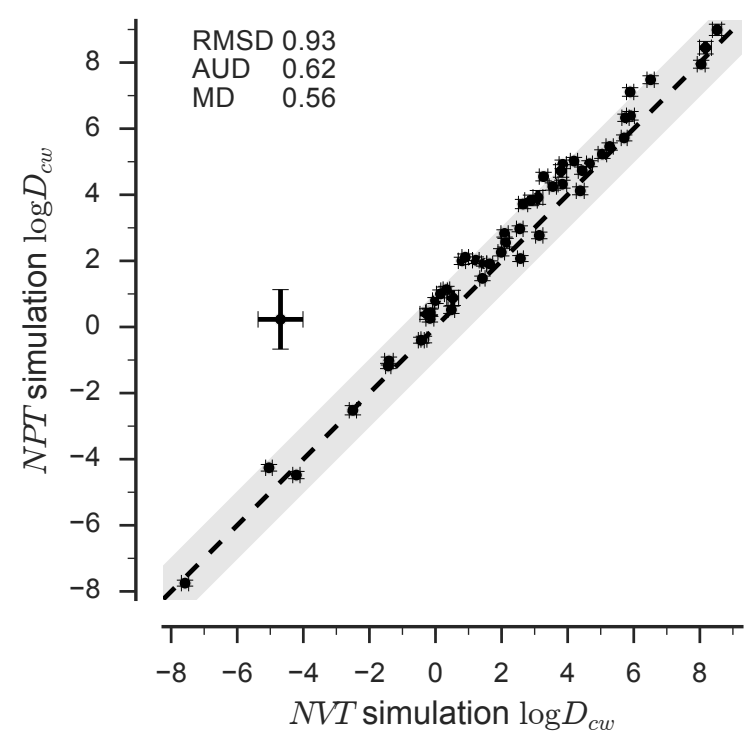

Fig. S2 Correlation between water-cyclohexane distribution coefficients $\log D_{c w}$ for simulations performed in the $N V T$ ensemble vs ones computed from the NPT ensemble. The obvious outlier is 083 . The gray band indicates $\pm 1 \log$-units from ideal correlation, shown by the dashed line. The root mean square deviation (RMSD), the absolute unsigned deviation (AUD), and the (signed) mean deviation (MD) are indicated. Error bars represent the error on the mean, derived from the simulations.

a high Kendall's $\tau=0.92$. Only compound $\mathbf{0 8 3}$ is very different between the two ensembles but this is almost certainly due to insufficient sampling: The simulations were only $1.5 \mathrm{~ns}$ instead of $15 \mathrm{~ns}$ and the compound is much larger and more complicated than the other compounds. With additional calculations of $15 \mathrm{~ns}$ simulations (NPT only) and using different initial conformations, the solvation free energies still differ by about $2 \mathrm{kcal} / \mathrm{mol}$ (see Table S1). It is thus likely that the $N V T$ value is not converged and the NPT value can only be seen as an initial guess. 